\title{
REPORTS OF SOCIETIES.
}

\section{THE ROYAL MEDICO-CHIRUGICAL SOCIETY OF GLASGOW.}

The seventh meeting was held on December, 7 th, 1945 , in the Faculty Hall, when three short papers were read on Oto-laryngological Subjects.

(1) . Mr. R. J. Watson: "The aetiology and treatment of otitis externa in the tropics."

(2) Mr. Ritchie Paterson: "Tuberculosis of the tonsils in relation to tuberculous cervical adenitis."

Mr. Paterson stated that of 161 cases in which the tonsils were submitted to histological examination mainly on a clinical diagnosis of tuberculous enlargement of the jugulo-digastric glands or gland, 57 (35 per cent.) were positive, Such a high incidence points very strongly to the advisability of enucleation of the faucial tonsils if possible as the first step in the treatment of tuberculous glands in the neck.

(3) . Mr.Tom Howie and Dr. George Bell: "The accomplishment of oesophageal speech."

It was shown by Mr. Howie that early laryngeal cancer can be treated with low recurrence rate by laryngofissure. More advanced cases require laryngectomy.

The mechanism of oesophageal speech was described and illustrated by lantern slides. The method of teaching it was sketched, and Dr. Bell played a gramophone recording of oesophageal speech by three laryngectomised patients.

\section{ROYAL COLLEGE OF SURGEONS OF EDINBURGH.}

At a meeting of the Royal College of Surgeons of Edinburgh, held on 19th December, Mr. Jas. M. Graham, President in the Chair, the following who passed the requisite examinations were admitted Fellows :-

Denis William Alexander Degazon, M.R.C.S.Eng., L.R.C.P. Lond. 1934 ; M.B., B.S. Univ. Lond. 1935.

Valter Harrison Fahrni, M.D. Univ. Manitoba, 1940.

John Fairlie Mair Frew, M.B., Ch.B. Univ. Glasgow, 1939.

Eric Garland-Collins, M.R.C.S.Eng., L.R.C.P. Lond. 1937 ; M.B., B.S. Univ. Lond. 1937.

Norman Otway Knight Gibbon, M.B., Ch.B. Univ. Liverpool 1941.

Robert Hodkinson, M.R.C.S.Eng., L.R.C.P. London 1928.

William Irving, M.B., B.S. Univ. Durham 1927.

Michael Joseph Kelleher, M.B., B.Ch., B.A.O. Nat. Univ. Ireland 1942.

John Hiram Kirkham, M.B., Ch.B. Univ. Birmingham 1940.

Jesse Richard Frank Mills, M.D. Univ. Toronto 1933, M.S. Univ. Toronto 1938.

Robert Crawford Rider, M.D. Univ. Ontario 1935 ; L.M.C. Canada 1935.

Ian Catto Simpson, M.B., Ch.B. Univ. Aberdeen 1936.

Frederick Smith, M.B., Ch.B. Univ. St. Andrews 1938.

William Mark Toone, M.D. Univ. Toronto 1937.

The following candidates having passed the requisite examinations were admitted Higher Dental Diplomates:-

William Smith Matheson, L.D.S., R.C.S.Edin. 1938.

Hamișh Thomson, L.D.S., R.F.P. \& S. Glasgow 1940. 